\title{
EPIDEMIOLOGIA DE LAS INFECCIONES VIRALES EN LA UNIDAD DE CUIDADOS INTENSIVOS NEONATALES. INSTITUTO NACIONAL MATERNO PERINATAL 2013 - 2014
}

\author{
Elina Mendoza Ibañez¹, Carmen Rosa Dávila Aliaga², María Morillo Acuña ${ }^{3}$, Elsa Torres Marcos ${ }^{4}$, \\ Pablo Velásquez Acosta 5 .
}

\begin{abstract}
RESUMEN
Objetivo. Conocer la epidemiologia de las infecciones virales en UCIN-INMP. Materiales y métodos. Revisión de 50 historias clínicas de pacientes con infección viral confirmada, en los años 2013 y 2014, de UCIN - INMP y análisis estadístico descriptivo, utilizando SPSS 23. Resultados. $62 \%$ de la muestra fueron menores de $1500 \mathrm{gr}, 80 \%$ de los casos fueron Influenza B, 4\% Influenza A y 14\% Virus Sincitial respiratorio. En el año 2013 las infecciones se presentaron con mayor frecuencia en Julio y Noviembre; y en el 2014 en Marzo, Julio y Agosto. Conclusiones. En los años 2013 y 2014 en la UCIN tuvimos 990 ingresos y 50 casos de enfermedades virales demostradas, lo cual representa una incidencia del $5 \%$. Igual que en otras series las enfermedades virales comprometen sobre todo a pretérminos de menos de $1500 \mathrm{gr}$. No encontramos estacionalidad definida de las presentaciones virales como en otras fuentes.
\end{abstract}

Palabras clave: Recién nacido; Prematuro; Virosis (Fuente: DeCS BIREME).

\section{EPIDEMIOLOGY OF VIRAL INFECTIONS IN NEONATAL INTENSIVE CARE UNIT. MATERNAL PERINATAL NATIONAL INSTITUTE 2013 - 2014}

\begin{abstract}
Objective. To determine the epidemiology of viral infections in the NICU-INMP. Materials and Methods. Review of medical records of 50 patients with confirmed viral infection, in 2013-2014 in the NICU -INMP and descriptive statistical analysis using SPSS 23 . Results. $62 \%$ of the sample were less than $1500 \mathrm{gr}, 80 \%$ cases were Influenza B, 4\% Influenza A and 14\% Respiratory Syncytial virus. In 2013 infections occurred more frequently in July and November and at 2014 in March, July and August. Conclusions. In the years 2013 and 2014 in the NICU were 990 patients and 50 cases of proven viral diseases, representing an incidence of $5 \%$. As in other series viral diseases especially involve preterms less than $1500 \mathrm{gr}$. We found indefinite seasonality of viral presentations unlike other sources.
\end{abstract}

Key words: Newborn;Premature;Virus diseases (Source:MeSH NLM).

\section{INTRODUCCIÓN}

Las infecciones son las patologias más relevantes que se atienden en las Unidades de Cuidado Intensivo Neonatal (UCIN), representan una de las tres principales causas de mortalidad en el período neonatal, juntos con la prematuridad y la asfixia ${ }^{1}$. La sepsis neonatal, respuesta inflamatoria sistémica desencadenada por un patógeno, clasicamente, ha sido causada por bacterias pero en las últimas decadas con mayor frecuencia se confirman hongos ó virus, debido a mayores recursos para su diagnóstico ${ }^{2,3}$
Según reportes internacionales las infecciones nosocomiales en las UCIN se han incrementado en las últimas décadas entre 6.2 a $30 \%{ }^{4}$. Las infecciones virales en los infantes hospitalizados en la UCIN no son reportados frecuentemente ya que existe una superposición de los signos y síntomas clínicos de la infección viral y otras condiciones patológicas en los neonatos críticamente enfermos ${ }^{5}$. Con el desarrollo de las técnicas diagnósticas rápidas y altamente sensibles como la Reacción de Cadena Polimerasa (PCR) mejoró la detección e identificación de infecciones virales. Desde la introducción de estas técnicas, el interés clínico de las

Médico Pediatra Neonatólogo. Profesor de la Facultad de Medicina Humana de la Universidad Particular San Juan Bautista. Jefe del Servicio de UCIN del Departamento de Neonatología del Instituto Nacional Materno Perinatal. Lima-Perú

Médico Pediatra Neonatóloga, Profesor de la Facultad de Medicina Humana de la Universidad Nacional Federico Villarreal. Directora Ejecutiva de Docencia, Investigación y Atención en Neonatología en el Instituto Nacional Materno Perinatal. Lima-Perú.

Médico Pediatra Neonatóloga del Servicio de UCIN, Departamento de Neonatología del Instituto Nacional Materno Perinatal. Lima-Perú.

4 Médico Pediatra Neonatóloga. Profesor de la Facultad de Medicina Humana de la Universidad Particular San Juan Bautista. Jefe del Servicio de Atención Inmediata del Departamento de Neonatología del Instituto Nacional Materno Perinatal. Lima-Perú.

5 Médico Pediatra Neonatólogo del Servicio de UCIN, Departamento de Neonatología del Instituto Nacional Materno Perinatal. Lima-Perú. 
infecciones virales se incrementó, sin embargo los datos epidemiológicos de las infecciones virales en la UCIN son aún escasos y frecuentemente limitados a la evaluación de brotes ${ }^{5-8}$

Las infecciones virales son causa de importante morbimortalidad, sobre todo en recién nacidos prematuros, ocasionan infecciones respiratorias altas y bajas, destacando el virus Sincitial respiratorio y el virus de la influenza. Su evolución, con tratamiento sintomático y antiviral en algunos casos, es por lo general favorable, aunque se describen formas graves en el recién nacido (RN) ${ }^{9.10}$

Gonzalez-Carrasco, estudiando aspirados nasofarigeos de RN pretermino menores de 32 semanas, reportó una tasa de $9 \%$ para infecciones virales ${ }^{11}$. En Chile, Bancalari, estudiando 260 recién nacidos hospitalizados por infección respiratoria aguda baja, aisló virus Sincitial respiratorio mediante inmunofluorescencia en 150 de ellos $(57,7 \%)^{12}$. Guinea en el 2007 , estudió 284 pacientes con bronquiolitis grave, $45 \%$ fueron menores de 6 semanas y $30 \%$ con antecedentes de prematuridad; reporta identificación del virus Sincitial respiratorio en $74 \%{ }^{13}$.

La UCIN del Instituto Nacional Materno Perinatal (INMP), cuenta con una capacidad instalada de 30 incubadoras, pero por ser un centro de referencia a nivel nacional, existe sobredemanda lo que muchas veces, produce hacinamineto y condiciones para la diseminación de patógenos, entre ellos los virus. El objetivo del presente trabajo fue conocer la epidemiologia de las infecciones virales en UCIN.

\section{MATERIAL Y METODOS}

Estudio descriptivo retrospectivo de recién nacidos que ingresaron a la UCIN del INMP de Enero 2013 a Diciembre 2014. Se revisó el libro de ingresos de la UCIN en busca de RN con diagnóstico de infección viral, se solicitaron las historias clínicas de todos los pacientes con infección viral confirmada, en busca de los datos de interes. La confirmación de infección respiratoria fue realizada mediante inmunofluorescencia indirecta (IFI) en secreciones orofaringeas y detección viral por reacción de cadena de polimerasa (PCR) en secreciones orofaringeas (pneumovir). A todo paciente con signología respiratoria y sospechoso de infección viral, se le solicitó IFI o pneumovir en secreciones orofaringeas. Se realizó estadística descriptiva y análisis estadístico usando SPSS versión 23

\section{RESULTADOS}

Durante el período de estudio, de un total de 990 ingresos a la UCIN, 50 fueron diagnosticados de infecciones respiratorias virales bajas, lo cual representa una incidencia del $5 \%$. De los cuales $58 \%$ fueron varones, $88 \%$ prematuros y $64 \%$ menores de $1500 \mathrm{gr}$, egresaron vivos $96 \%$. El $82 \%$ de nuestra población fue paciente hospitalizado. La distribución de acuerdo a la procedencia se puede ver en la Tabla 1.

Tabla 1. Distribución por procedencia de RN con infección respiratoria viral en la UCIN. 2013-2014 INMP

\begin{tabular}{lcc}
\hline PROCEDENCIA & $\mathbf{N}^{\circ}$ & $\%$ \\
\hline Domicilio & 8 & 16 \\
INMP & 41 & 82 \\
Otro hospital & 1 & 2 \\
Total & 50 & 100 \\
\hline
\end{tabular}

El peso al nacimiento es determinante para estas infecciones y sus complicaciones, en nuestra serie encontramos una incidencia del $92 \%$ en RN con peso menor de $2500 \mathrm{~g}$. con una relación inversamente proporcional en relación al peso de nacimiento, siendo mucho más frecuente en los RN menores de $1000 \mathrm{~g} \mathrm{(38 \% ).}$ Tabla 2. La edad gestacional es un factor importante en la epidemiología de las infecciones virales, ya que en el RN prematuro, los mecanismos de inmunidad celular y producción de anticuerpos es deficiente con respecto a RN a término, lo que se correlaciona con nuestros hallazgos, en donde el $88 \%$ de infecciones ocurrieron en RN menores de 37 semanas, $66 \%$ en menores de 32 semanas y $34 \%$ entre 28 a 31 semanas de $E G$.

Tabla 2. Recién nacidos según peso al nacimiento con infección respiratoria viral en la UCIN. 2013-2014 INMP

\begin{tabular}{lccc}
\hline PESO gr & $\mathrm{N}^{\circ}$ & $\%$ & $\%$ acumulado \\
\hline$<1000$ & 19 & 38 & 38 \\
$1000-1499$ & 13 & 26 & 64 \\
$1500-2499$ & 14 & 28 & 92 \\
$2500 \mathrm{a}+$ & 4 & 8 & 100 \\
Total & $\mathbf{5 0}$ & $\mathbf{1 0 0}$ & \\
\hline
\end{tabular}

La edad de diagnóstico de la infección respiratoria ocurrió con más frecuencia después de los 14 días de edad post natal $(74 \%)$, con extremos de 8 días y más de 28 días. Tabla 3.

Tabla 3. Edad postnatal al diagnóstico de infección respiratoria viral en UCIN 2013-2014 INMP

\begin{tabular}{ccc}
\hline $\begin{array}{c}\text { EDAD AL } \\
\text { DIAGNOSTICO/DÍAS }\end{array}$ & $\mathbf{N}^{\circ}$ & $\%$ \\
\hline $8-14$ & 13 & 26 \\
$15-28$ & 18 & 36 \\
$>28$ & 19 & 38 \\
Total & 50 & 100 \\
\hline
\end{tabular}

En cuanto al requerimiento de oxigeno en sus diferentes fases, $40 \%$ estaba en ventilación mecánica (Fase III) al diagnóstico, $10 \%$ pasó de oxigenoterapia con cánula binasal (fase I) a CPAP (Fase II), $8 \%$ pasaron de fase II a III y $4 \%$ de aire ambiental a fase II. El $38 \%$ requirió oxígeno de 1 a 7 días, $24 \%$ de 15 a 28 días, $16 \%$ de 8 
a 14 días, $10 \%$ más de 28 días y $12 \%$ no requirieron oxigenoterapia. Tabla 4.

Tabla 4. Variación en el uso de oxígeno en $\mathrm{RN}$ con infección respiratoria viral en la UCIN 2013-2014 INMP

\begin{tabular}{lcc}
\hline O2 AL DIAGNOSTICO & $\mathbf{N}^{\circ}$ & $\%$ \\
\hline Fase III & 20 & 40 \\
Fase I a II & 10 & 20 \\
Fase II a III & 4 & 8 \\
Aire amb/fase II & 2 & 4 \\
Aire amb/fasel & 8 & 16 \\
No oxígeno & 6 & 12 \\
& 50 & 100 \\
\hline
\end{tabular}

En cuanto a la estacionalidad, para el virus Sincitial respiratorio durante el período de estudio el año 2013, $57 \%$ de las infecciones se presentaron en el mes de Noviembre y $28 \%$ en Julio; en el 2014 las infecciones se presentaron con mayor frecuencia en los meses Marzo $28 \%$, Julio $28 \%$ y Agosto $24 \%$ (Gráfico 1 ).

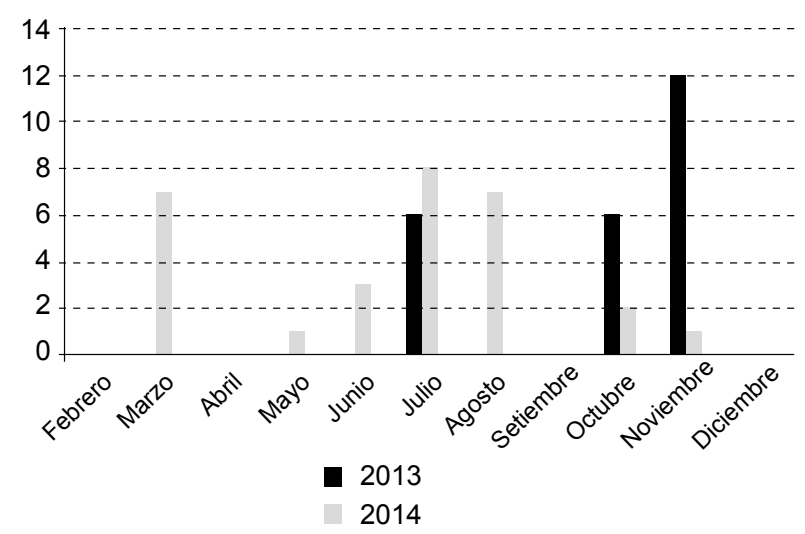

Gráfico 1. Estacionalidad de las infecciones virales en la UCIN 2013-2014 INMP

El estudio IFI de hisopado faríngeo se realizó en $100 \%$ de los casos. Se confirmó en $80 \%$ Influenza B, $4 \%$ Influenza A, $14 \%$ Virus Sincitial respiratorio, 2\% Parainfluenza. Tabla 5.

Tabla 5. Aislamiento viral en RN con infección respiratoria viral en la UCIN. 2013-2014 INMP

\begin{tabular}{lcc}
\hline VIRUS & $\mathrm{N}^{\circ}$ & $\%$ \\
\hline Influenza B & 40 & 80 \\
Influenza A & 2 & 4 \\
VRS & 7 & 14 \\
Parainfluenza & 1 & 2 \\
\hline
\end{tabular}

El 98\% de los pacientes diagnosticados con infección por influenza, recibieron como tratamiento OSELTAMIVIR por vía enteral durante 5 días y se mantuvieron en aislamiento durante 10 días para evitar la diseminación. El $20 \%$ de los casos presentó alguna complicación, de las cuales $70 \%$ fueron atelectasias, $20 \%$ neumonía y $10 \%$ neumotórax. Tabla 6.
Tabla 6. Complicaciones asociadas en RN con infección respiratoria viral en la UCIN. 2013-2014 INMP

\begin{tabular}{cccc}
\hline $\begin{array}{c}\text { TIPO } \\
\text { COMPLICACIÓN }\end{array}$ & $\mathbf{N}^{\circ}$ & $\mathbf{\%}$ & $\begin{array}{c}\text { Del total } \\
\mathbf{5 0}\end{array}$ \\
\hline Neumonia & 2 & 20 & $4 \%$ \\
Atelectasia & 7 & 70 & $14 \%$ \\
Neumotórax & 1 & 10 & $2 \%$ \\
TOTAL & & 100 & $20 \%$ \\
\hline
\end{tabular}

\section{DISCUSIÓN}

Las infecciones virales en neonatos hospitalizados en la UCIN se producen de forma paralela a otras enfermedades graves; dentro de los virus más frecuentes se encuentran: virus Sincitial respiratorio, influenza $A$, influenza $B, y$ otros; los cuales pueden presentarse como brotes, de allí que la detección de estos patógenos requieren de alta sospecha clínica debido a que los síntomas de infección viral son inespecíficos: apnea, inestabilidad térmica, intolerancia alimentaria, etc. Así mismo, los RN pueden portar el virus por tiempo prolongado contaminando el ambiente y facilitando su propagación entre los pacientes hospitalizados cuando se rompen las barreras de control de infecciones o de bioseguridad por el personal de salud ${ }^{14}$.

Los factores de riesgo para la adquisición de la infección incluyen: peso al nacimiento, prematuridad, embarazo gemelar, uso de ventilación mecánica, cardiopatías congénitas cianóticas o complicadas que cursan con hipertensión pulmonar, displasia broncopulmonar, estancia prolongada, inmunodeficiencia o con tratamiento que causa inmunodepresión y puntaje alto de CRIB ${ }^{15,16}$

Al igual que en otras series nosotros encontramos que el mayor número de casos se dio en pacientes hospitalizados $82 \% \quad 11,13,17,18$;la población más afectada son los prematuros menores de 32 semanas $(66 \%)$, los de extremo bajo peso son los más vulnerables debido a las diferentes morbilidades que presentan ${ }^{19}$.

La edad de confirmación diagnóstica en $74 \%$ de nuestros casos, fue luego de la segunda semana de vida, lo cual podría explicarse por los altos niveles de anticuerpos maternos presentes en la primera semana de vida que ofrecen protección al $\mathrm{RN}$ y que es responsable de los cuadros atípicos en RN prematuros en los que falta el componente obstructivo ${ }^{20}$.

Las necesidades de ventilación mecánica en $\mathrm{RN}$ con infección viral son mayores en nuestra serie (40\%) que la reportada en la serie de Bancalari ${ }^{12}$, debido a que nuestra muestra está conformada principalmente por prematuros que tienen otras patologías asociadas, a diferencia de aquella, donde eran mayormente $\mathrm{RN}$ a término. En general los pacientes con una infección viral baja incrementaron su requerimiento de oxígeno (48\%), aquellos en los que no hubo variación en el tipo de oxigenoterapia, se apreció elevación de fracción inspirada de oxígeno $(40 \%)^{9}$. 
En el presente estudio no se apreció estacionalidad de las infecciones virales durante los 02 años del estudio, probablemente por la variabilidad climática actual, las estaciones no son tan definidas, ni respetan los meses usuales, en nuestro país los virus como influenza y virus Sincitial respiratorio tienen una distribución anual. La literatura relaciona las infecciones virales a los meses invernales ${ }^{5}$.

En nuestra serie el virus más frecuentemente identificado fue Influenza B $(80 \%)$, seguido por Virus Sincitial respiratorio $(14 \%)$.

Aunque los brotes por virus de Influenza son raros en la población neonatal, más aún casos fatales, debido a la presencia de anticuerpos maternos ${ }^{21}$. Muñoz y cols reportaron un brote de infección por influenza $A$ en una UCIN de Houston, Texas. La unidad de 20 camas tuvo 15 casos $^{22}$

Cunney y cols, reportaron un brote de Influenza A en una UCIN en Ontario, Canadá de 54 pacientes en la unidad, $35 \%$ se infectaron con el virus, de los cuales $30 \%$ fueron sintomáticos y $5 \%$ falleció. Aislaron el virus de la influenza en aspirado nasofaríngeo por inmunofluorescencia. El caso índice curso con deterioro respiratorio a la edad de 14 días. Las medidas de control adoptadas fueron: aislamiento, tamizaje a todos los pacientes de la unidad cada 2 a 3 días de acuerdo al periodo de incubación. El flujo de aire de los cuartos de los casos y los contactos fue mantenido con presión negativa relativa a las otras habitaciones. La UCIN fue cerrada a admisiones externas. Los neonatos requirieron 2 tamizajes negativos para considerarlos limpios ${ }^{23}$

En el presente estudio los pacientes diagnosticados de influenza, recibieron tratamiento con osetalmivir por vía enteral, en todos los casos se realizaron medidas de acuerdo a protocolo de control de infecciones y aislamiento durante 10 días para evitar la diseminación ${ }^{24}$.

La segunda causa de infección viral baja en nuestra serie fue el virus Sincitial respiratorio (VRS), este agente según la literatura, tiene distribución universal, provoca epidemias anuales durante el invierno y principios de la primavera en los climas templados y por su frecuencia y eventual gravedad representa un importante problema de Salud Pública ${ }^{16,20,25}$. Hay numerosas publicaciones sobre la aparición de brotes nosocomiales. Estos brotes se asocian con el quiebre de las normas de prevención de infecciones nosocomiales y la necesidad de un mayor grado de procedimientos invasivos. En el 0.5 al $1.5 \%$ la enfermedad puede ser grave, requerir hospitalización, oxigeno suplementario y asistencia respiratoria ${ }^{17,18,26,27}$.

El período de incubación varía de 2 a 8 días ${ }^{25}$. EI VSR se transmite a través del contacto directo con secreciones infectadas, pero no tiene transmisión por aerosoles de partículas pequeñas ${ }^{16,28}$. La inmunofluorescencia y enzimo-inmunoanálisis para detectar antígeno viral son pruebas confiables. La sensibilidad en comparación con los cultivos varía del 53 al $96 \%$. El grupo de mayor riesgo son prematuros, principalmente si cursan con displasia broncopulmonar, cardiopatías y estados de inmunodepresión. La mortalidad por infección por VSR puede llegar al $5 \%$, aún en países industrializados ${ }^{19}$. Las diferencias antigénicas pueden afectar la susceptibilidad a la infección y algunas cepas pueden ser más virulentas que otras. La inmunidad no es permanente, aparecen re-infecciones y existen observaciones que altos títulos de anticuerpos circulantes y secretorios anti VRS en la fase aguda de la reinfección no siempre correlacionan con mejoría clínica más rápida ${ }^{5,29}$.

En el estudio de Malgorzata y cols. en un período de 12 años, de una cohorte de pretérminos menores de 32 semanas de edad gestacional y/o peso menor de 1,500 gramos. La infección viral fue confirmada en 51 casos de 5,396 neonatos (1\%) admitidos a la UCIN, en $29 \%$ se reportó virus Sincitial respiratorio (VSR), 4\% adenovirus, $4 \%$ Para influenza y $2 \%$ a rinovirus. La infección a VSR se desarrolló predominantemente en pacientes hospitalizados $(60 \%)$ y $93 \%$ de las infecciones ocurrió durante el invierno ${ }^{30}$.

La literatura menciona que las medidas de aislamiento y control son fundamentales para evitar la propagación de las infecciones virales, por otro lado, consideran la posibilidad de adelantar la administración de palivizumab (PVZ) durante el brote nosocomial a los niños que son tributarios de recibirlo al alta si existen tres o más niños afectos de VSR en la unidad ${ }^{31}$.

La complicación encontrada con mayor frecuencia fue atelectasia $(70 \%)$, lo cual fue reportado también por otros autores.

\section{CONCLUSIONES}

En los años 2013 y 2014 tuvimos una incidencia de infecciones virales bajas del $5 \%$, en su mayoría prematuros menos de $1500 \mathrm{gr}$.

El $74 \%$ se infectó a los 15 días de vida post natal, estas infecciones elevó en su mayoría el requerimiento de oxígeno.

No encontramos estacionalidad de las infecciones, el virus más frecuentemente hallado fue influenza B $90 \%$ y en segundo lugar $14 \%$ virus Sincitial respiratorio.

Los casos de infección por Influenza recibieron tratamiento con osetalmivir, con buena respuesta al tratamiento. La complicación más frecuente fue atelectasia.

\section{RECOMENDACIONES}

Es necesario el cumplimiento estricto de los procedimientos de control de infecciones, como prevención de la 
contaminación ambiental por secreciones respiratorias y la cuidadosa higiene de manos para controlar la transmisión nosocomial y reducir la diseminación de la enfermedad en las salas de hospitalización.

Es importante contar con fisioterapia respiratoria dentro del manejo integral de estos pacientes, a fin de prevenir y/o tratar la complicación más frecuente que es la atelectasia. Es necesario realizar y difundir una estricta vigilancia del comportamiento de agentes virales causantes de infecciones respiratorias bajas en nuestro país a lo largo de los meses del año.

\section{REFERENCIAS BIBLIOGRAFÍCAS}

1. Liu L, Johnson HL, Cousens S, Perin J, Scott S, Lawn JE, et al. Global, regional, and national causes of child mortality: an updated systematic analysis for 2010 with time trends since 2000. The Lancet. 2012;379(9832):2151-2161.

2. Cotallo GC, Fernández Al. Protocolos de Neonatología. Bol Pediatr. 2006;46(SUPL 1):125-134.

3. Vij NK, Stryker CC, Esper FP, Jacobs MR, Gonzalez BE. Influenza A/H1N1/09-10 Infections in a NICU During the 2009-2010 H1N1 Pandemic. Pediatrics. 2011;128(5):e1297e1301.

4. Clark R, Powers R, Bloom b, Sanchez P, Benjamin DK Jr. Nosocomial Infection in the NICU: a medical complication or unavoidable problem? J Perinatol 2004; 24:382-86.

5. Hall CB, McCarthy CA. Respiratory syncytial virus. In: Mandell GL, Bennett JE, Dolin R, eds. Principles and Practice of Infectious Disease. 4 th. ed. New York: Churchill Livingston Publishers; 1995:1501-1519.

6. Gelbert SE, Ratner AJ. Hospital -acquired viral pathogens in the neonatal intensive care unit. SeminPerinatol. 2002; 26:346-356.

7. Abzug MJ, Loeffleholz M, Rotbart HA. Diagnosis of neonatal enterovirus infection by polymerase chain reaction. $J$ Peditr. 1995; 126:447-450.

8. Muñoz FM, Campbell JR, Atmar RL, et al. Influenza A virus outbreak in a neonatal intensive care unit. Pediatr Infect Dis J 1999; 18:811-15.

9. Aujard Y. Infecciones neonatales de origen viral. EMCPediatría. 2013;48(2):1-9.

10. Krilov LR. Respiratory syncytial virus disease: update on treatment and prevention. Expert Rev Anti Infect Ther. 2011;9(1):27-32.

11. Gonzalez-Carrasco E, Calvo C, García-García ML, Beato M, Muñoz-Archidona C, Pozo F, et al. Infecciones virales de las vías respiratorias en la Unidad de Cuidados Intensivos Neonatales. In: Anales de Pediatría [Internet]. Elsevier; 2015 [cited 2016 May 27]. p. 242-246.

12. Bancalari M, Martínez A, Casanueva $C$, Véliz $C$, Walker $C$, Opazo R, et al. Etiología viral en la infección respiratoria aguda baja en recién nacidos. Rev Chil Pediatría. 1999;70(3):201-207.

13. Guinea AL, Flores JC, Docio BE, de la Calle Cabrera $T$, Serrano A, others. Bronquiolitis grave. Epidemiología y evolución de 284 pacientes. In: Anales de Pediatría [Internet]. Elsevier; 2007 [cited 2016 May 27]. p. 116-122.
14. Remington and Klein. Heath J, Zerr D. Infections acquired in the nursery epidemiology and control in Infectious diseases of the fetus and newborn infant. Elsevier.2006: 1187.

15. Tsusumi $\mathrm{H}$ y colaboradores. Systemic and local immune response of four cases with lower respiratory tract illness due to reinfection with respiratory syncytial virus. J Infect 1997;35:189-192.

16. Bont L. Nosocomial RSV infection control and outbreak management. Paediatr Respir Rev. 2009;10suppl 1):16-17

17. Ditchburn RK, McQuillin J, Gardner PS, Court SDM. Respiratory syncytial virus in hospital cross-infection. BMJ. 1971;3:671-73.

18. Douglas RG, Geiman JM, Messner MK. Nosocomial respiratory syncytial virus infections. N Engl J Med. 1975;293:1343e1346;

19. Ruotsalainen M, Piippo-Savolainen E, Hyvarinen MK, Korppi M. Respiratory morbidity in adulthood after respiratory syncytial virus hospitalization in infancy. Pediatr Infect Dis $\mathrm{J}$. 2010;29:872-4.

20. Hall $C B$, McCarthy CA. Respiratory syncytial virus. In: Mandell GL, Bennett JE, Dolin R, eds. Principles and Practice of Infectious Disease. 4 th. ed. New York: Churchill Livingston Publishers; 1995:1501-1519.

21. Puck JM, Glezen WP, Frank Al. proteccion of infants from infection with influenza $A$ virus by transplacentally acquired antibody. J infect Dis 1980;142:844-849 .

22. FM Muñoz, J Campbell, R Atmar Pediatr Influenza A virus outbreak in neonatal intensive care unit. Infect Dis J 18, 8115, 1999.

23. Cunney R MB, Bialachowsky, BN, et al. An outbreak of Influenza $A$ in a Neonatal Intensive Care Unit. Infec ControlHospEpidemiol 2000; 21:449-454.

24. Navin K. Vij, et al. Influenza A/H1N109-10 Infections in a NICU During the 2009-2010 H1N1 Pandemic. Pediatrics 2011;128;e1297.

25. Giubergia V, Martinchuk G, Moreno N, Colombres G. Gravedad de la infección por virus sincicial respiratorio en pacientes con factores de riesgo y sin ellos. Arch. argent. pediatr 2004; 102(5):330-334.

26. Garcia Perez A, Caritg Bosch J, Junconsa Morros T, Krauel Vidal J. Outbreak of respiratory syncytial virus in a neonatal unit. an Esp Pediatr 1989;30:480e482;

27. Langley JM, LeBlanc JC, Wang EE, Law BJ, MacDonald NE, et al. Nosocomial respiratory syncytial virus infection in Canadian pediatric hospitals: a Pediatric Investigators Collaborative Network on Infections in Canada Study. Pediatrics. 1

28. Goldmann DA. Transmission of viral respiratory infections in the home. Pediatr Infect Dis J. 2000;19:S97-S102.

29. Tsutsumi $\mathrm{H}$ y colaboradores. Systemic and local immune response of four cases with lower respiratory tract illness due to reinfection with respiratory syncytial virus. J Infect 1997;35:189-192.

30. Malgorzata A, Verboon-Maciolek, MD et al. Clinical and Epidemiologic characteristics of Viral Infections in a Neonatal Intensive Care Unit During a $12-$ Year Period. Pediatr Infect Dis J 2005; 24:901-4.

31. Committee On Infectious Diseases And Bronchiolitis Guidelines Committee. Pediatrics 10.1542/peds.2014-1666; originally published online July 28,$2014 ; 2014 ; 134$; e620. Downloaded from pediatrics.aappuications.org by guest on August 7, 2014. 